\title{
Summary statistics for drug concentrations in post-mortem femoral blood representing all causes of death
}

\section{Ketola, Raimo A.}

2019-09

Ketola , R A \& Ojanperä , I 2019 , ' Summary statistics for drug concentrations in post-mortem femoral blood representing all causes of death ' , Drug Testing and Analysis , vol. 11 , no. 9 , pp. 1326-1337 . https://doi.org/10.1002/dta.2655

http://hdl.handle.net/10138/315208

https://doi.org/10.1002/dta.2655

unspecified

acceptedVersion

Downloaded from Helda, University of Helsinki institutional repository.

This is an electronic reprint of the original article.

This reprint may differ from the original in pagination and typographic detail.

Please cite the original version. 


\section{Summary statistics for drug concentrations in post-mortem}

\section{femoral blood representing all causes of death}

Raimo A. Ketola ${ }^{1}$ and Ilkka Ojanperä ${ }^{1,2}$

${ }^{1}$ National Institute for Health and Welfare, Forensic Toxicology, P.O. Box 30, FI-00271 Helsinki, Finland

${ }^{2}$ Department of Forensic Medicine, P.O. Box 40, FI-00014 University of Helsinki, Finland

Corresponding author: Professor Ilkka Ojanperä, Department of Forensic Medicine, P.O. Box 40

(Kytösuontie 11), FI-00014 University of Helsinki, Finland

E-mail: $\underline{\text { lkka.ojanpera@helsinki.fi }}$

Phone: $+358-40-585-1980$ 


\begin{abstract}
Concentration distributions for 183 drugs and metabolites frequently found in post-mortem (PM) femoral venous blood were statistically characterized based on an extensive database of 122234 autopsy cases investigated during an 18-year period in a centralized laboratory. The cases represented all causes of death, with fatal drug poisonings accounting for $8 \%$. The proportion of males was $74 \%$ with median age 58 years compared with $26 \%$ females with median age 64 years. In $36 \%$ of these cases, blood alcohol concentration was higher than or equal to $0.2 \%$, the median being $1.6 \%$. The mean, median, and upper percentile $\left(90^{\text {th }}, 95^{\text {th }}, 97.5^{\text {th }}\right)$ drug concentrations were established, as the median PM concentrations give an idea of the 'normal' PM concentration level, and the upper percentile concentrations indicate possible overdose levels. A correspondence was found between subsets of the present and the previously published PM drug concentrations from another laboratory that used grouping of cases according to the cause of death. Our results add to the knowledge for evidence-based interpretation of drug-related deaths.
\end{abstract}

Keywords: post-mortem toxicology; post-mortem drug redistribution; cause of death; drug concentration; post-mortem blood 


\section{Introduction}

Organized post-mortem (PM) toxicology service provides legal protection for both individuals and society and has an increasing impact on welfare and health as drug use is becoming more prevalent. During the last decades there has been considerable progress in many facets of the discipline, including development of analytical methods, understanding of post-mortem changes, and interpretation of results. ${ }^{1}$ Current quality-assured analytical results and their evidence-based interpretation make medico-legal cause-of-death investigation more reliable and improve the quality of death certificates. As national mortality statistics are based on death certificates, the information obtained from high-quality death certificates will, in turn, help authorities and policymakers to recognize trends of drug misuse and abuse and carry out the necessary interventions, thus improving drug safety. ${ }^{2-4}$

In cause-of-death investigation, clinical history, autopsy findings and the totality of laboratory results have to be interpreted together. PM concentrations of drugs and poisons play a major role in the interpretation, but it is important to realize that reference ranges for PM concentrations are only one of the crucial elements in the process. Laboratories usually possess in-house databases of varying size with data gathered from case work. In addition, published case notes or small case series, as well as compilations collected from literature sources are available, ${ }^{5}$ but these data are often heterogeneous in terms of the sampling site, the analytical methods used, and the number of cases involved. There may even be a bias of publishing mainly cases with exceptionally high concentrations.

The fact that PM drug concentrations are not necessarily the same as those at the time of death, called the PM drug redistribution (PMR), was brought to attention by Prouty and Anderson in their two papers published in 1987 and 1990, ${ }^{6,7}$ as well as by Pounder and Jones in $1990,{ }^{8}$ but similar observations had been made much earlier. ${ }^{9}$ Drug levels may vary according to the sampling site and the interval between death and specimen collection (PM interval). In optimal circumstances, a sample 
of PM venous blood from a femoral vein is taken as soon as possible after death, as this procedure is considered to give results that are the least susceptible to PM change..$^{10,11}$

Systematic collection and evaluation of reference concentrations in PM femoral blood have been carried out by Swedish investigators, ${ }^{12}$ taking advantage of the relatively high PM toxicology rate and uniform procedures in the country. In this approach, the cases are subdivided into poisonings by one specific substance only (Group A), multi-substance poisonings (Group B), and PM controls comprising deaths not involving incapacitation by substances (Group C). Moreover, the results are compared with data based on therapeutic drug monitoring and data collected from driving under the influence cases. This approach produces extremely valuable results, but the information retrieval is rather slow and laborious due to manual, multi-reviewer, case-by-case evaluation. Moreover, the number of cases especially in Group A may remain low, consisting of only a few concentration entries or no entries at all.

Another systematic approach that relies on a high PM toxicology rate is to utilize the PM concentrations that accumulate during case work without pre-selection for cause of death. This "allcauses-of-death approach", introduced by Jones and Holmgren, ${ }^{13}$ is more straightforward and prolific regarding the number of cases and drugs involved, omitting the tedious manual case grouping step. Also based on the Swedish material, these authors published concentration distributions of 25 drugs most frequently identified in PM femoral blood.

Finland is another country with a high PM toxicology rate and a centralized laboratory investigation. According to the law, all sudden and unexpected deaths undergo a medico-legal investigation, initiated by the police and conducted by a forensic pathologist. Specific grounds for the investigation include an obvious or suspected accident, suicide, crime, poisoning, occupational disease or medical treatment. As a result, in nearly $20 \%$ of all deaths a medico-legal investigation is performed. 
In our former paper, we followed the all-causes-of-death approach and published the PM median, mean, and upper percentile $\left(90^{\text {th }}, 95^{\text {th }}, 97.5^{\text {th }}\right)$ concentrations calculated for 129 drugs based on 57 903 Finnish autopsy cases with PM toxicology executed. ${ }^{14}$ In the present study, our main objective was to make the results of the original study more complete by extending the range to cover 183 drugs and metabolites, based on an even larger amount of accumulated data as a basis for the PM concentrations. Another objective was to compare our results with those published by the Swedish investigators.

\section{Materials and methods}

\section{Toxicological analysis}

The Finnish medico-legal system and the PM toxicology services were described in detail in our previous paper. ${ }^{14}$ Briefly, the concentration data were acquired from femoral venous blood taken at autopsy, the samples containing $1 \% \mathrm{NaF}$ and stored at $4^{\circ} \mathrm{C}$ prior to analysis. The blood samples were quantitatively monitored for about 200 drugs on a routine basis using three comprehensive methods. For acidic and neutral drugs, dual-column gas chromatography with nitrogen phosphorus detection (GC-NPD) ${ }^{15}$ was used until replaced in February 2007 by a method based on GC coupled with mass spectrometry (GC-MS). ${ }^{16}$ For benzodiazepines, a GC method with electron capture detection (GCECD $)^{17}$ was used until March 2010, after which a method based on GC and negative-ion chemical ionization MS (GC-NCIMS) ${ }^{18}$ was adopted for routine use. A dual-column GC-NPD method was used for basic drug screening ${ }^{19}$ until December 2014, when a method based on ultra-highperformance liquid chromatography with a photodiode array detector and a corona charged aerosol detector (UHPLC-DAD-CAD) was put into operation. ${ }^{20}$ Digoxin was analysed with an immunological method using Siemens Immulite 1000 or 2000XPi analyzers. Lithium was analysed by inductively coupled plasma mass spectrometry (ICP-MS) until February 2014, followed by a 
method based on an ion-selective electrode. Confirmation and additional determinations were carried out by GC-MS and LC-MS/MS for drugs not covered by the comprehensive quantitative monitoring methods described above. All the concentration results were obtained by using quality-controlled and mostly accredited methods that relied on calibration with appropriate reference standards. Along with the changes in the analytical methods, the lower limit of quantification (LOQ) changed for some compounds (Table 2).

\section{Data refining}

During the period between 1 January 2000 and 31 December 2017 the results from quantitative analyses of drugs in PM femoral venous blood from 122234 autopsy cases were entered into the toxicology database (Table 1). From this material, those drugs that had been quantified at least 18 times in PM blood were selected, and the median, mean, and upper percentile $\left(90^{\text {th }}, 95^{\text {th }}, 97.5^{\text {th }}\right)$ concentrations $(\mathrm{mg} / \mathrm{L})$ were calculated from the findings (Table 2).

\section{Comparison to literature reference concentrations}

In Table 2, a one point reference concentration value in living persons' plasma $\left(\mathrm{C}_{\text {plasma }}\right)$ was given for each drug to enable instant comparison with the PM concentrations. In most cases, the $\mathrm{C}_{\text {plasma }}$ values represented the upper limit of plasma/serum concentrations (in general, trough at steady state) observed following therapeutically effective doses. ${ }^{21}$

Comparison to the PM concentrations from the Swedish investigators' studies ${ }^{22-26}$ was based on the following concentration percentile ratios obtained from the two databases (Swedish/Finnish): median/median, $90^{\text {th }}$ percentile/median, $90^{\text {th }} / 90^{\text {th }}$ percentile, and $90^{\text {th }} / 97.5^{\text {th }}$ percentile. First, the concentration percentile ratios were calculated for individual drugs, and second, the medians of these ratios were calculated and presented in Table 3. 


\section{Results and discussion}

Table 1 shows demographics of the 122234 autopsy cases from the 18-year study period for which a comprehensive PM drug analysis was completed. The number of autopsies, the mean age, and the mean blood alcohol concentration $(\mathrm{BAC})$ in cases where it exceeds the LOQ of $0.2 \%$ ( $\mathrm{g} / \mathrm{kg})$ are given separately for males and females. The number of accumulated autopsy cases forming the basis of the concentration data is about twice the size of that in our original study, ${ }^{14}$ while the concentration data presented in that study forms a part of the present data. The demographics of the cases are fairly similar between these two studies in terms of gender distribution, age, and proportion of alcoholpositive cases. Males and females represented 74 and $26 \%$ of the subjects, respectively, and the median age was 58 and 64 years, respectively. The prevalence of alcohol-positive cases was $36 \%$ and the median BAC was 1.6\% . These figures showed little difference from the original study. ${ }^{14}$

Table 2 shows the concentration distributions in PM femoral venous blood for the 183 drugs and metabolites most frequently found in autopsy cases in alphabetical order, comprising 221780 individual concentration entries. There is an increase of 54 substances relative to the original study. Indicated are the number of cases, the LOQ, the PM mean, median, and upper percentile $\left(90^{\text {th }}, 95^{\text {th }}\right.$, 97. $5^{\text {th }}$ ) concentrations. As stated in the original study, the median PM concentrations are likely to give an idea of the 'normal' PM concentration range, and the upper percentile concentrations indicate possible overdose levels. This judgment is supported by the fact that the manner of death is natural in approximately 55\% of all PM toxicology cases in Finland, and the proportion of fatal drug poisonings in the present material was on average $8 \%$. However, this concept of normal and overdose levels cannot be applied to each drug in a mechanical manner.

Table 2 also lists clinical $\mathrm{C}_{\text {plasma }}$ values to roughly illustrate how the median PM femoral blood drug concentrations relate to the therapeutic ranges reported mainly in an established data compilation by Schulz et al. ${ }^{21}$ Calculating the PM median/C $/ \mathrm{C}_{\text {plasma }}$ ratio one can get an idea of the $\mathrm{PM}$ behavior for a 
particular drug. Apart from the PMR, exceptionally high $\mathrm{PM}$ median $/ \mathrm{C}_{\text {plasma }}$ ratio values may arise from a high intrinsic clinical blood/plasma ratio and/or a high volume of distribution, as exemplified by dextromethorphan and hydroxychloroquine, or from the high proportion of poisonings by a particular drug in the database, as exemplified by dextropropoxyphene and promazine. Correspondingly, exceptionally low values may arise from a low clinical blood/plasma ratio, as exemplified by aripiprazole, warfarin, and some benzodiazepines. Obviously, the representativeness

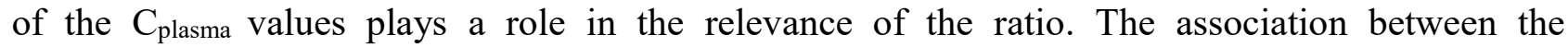
pharmacological characteristics remarked above and the PM concentration levels has been discussed in more detail in our previous study. ${ }^{14}$

Table 2 shows the relative differences in the PM median concentrations between the present database and the original database. For 18 drugs, the median concentration in the present database was more than $10 \%$ higher, and for 38 drugs it was more than $10 \%$ lower than in the original database. The mean (median) difference in the PM median concentrations between the databases was $-5 \%(0 \%)$, and the mean (median) difference in the absolute values was $13 \%(8 \%)$. These findings suggest that the PM median concentrations are largely reproducible over the course of time, though there were some exceptions concerning individual drugs. The reasons for a more prominent change include a relatively low or a much changed number of cases, changed clinical prescription practices or changed abuse patterns. While LOQ is an important factor relative to the statistical concentration distribution, the current changes in LOQ were generally associated with only minor effects on the results.

Table 3 shows the comparison of selected concentration percentiles in PM femoral venous blood between the present study, involving all causes of death $(\mathrm{N}=144034)$, and the five Swedish studies $(\mathrm{N}=9436)$, employing grouping according to the cause of death. ${ }^{22-26}$ A moderate correspondence was obtained between Swedish group C and our median concentration, both representing a 'normal' PM concentration. The median ratios of Swedish group C median to our median and Swedish group 
C $90^{\text {th }}$ percentile to our median were 0.6 and 1.7 , respectively. For example, in case of the antipsychotic drug olanzapine, our median concentration was $0.20 \mathrm{mg} / \mathrm{L}$, while the Swedish group C median and $90^{\text {th }}$ percentile were $0.10 \mathrm{mg} / \mathrm{L}$ and $0.20 \mathrm{mg} / \mathrm{L}$, respectively. ${ }^{25}$ A correspondence also existed between the Swedish group A and B $90^{\text {th }}$ percentiles and our $97.5^{\text {th }}$ percentile (ratios 1.2 and 0.9 , respectively), representing lethal concentrations for most substances. Similarly, as exemplified by olanzapine, our $97.5^{\text {th }}$ percentile concentration was $2.4 \mathrm{mg} / \mathrm{L}$, while the Swedish group A and B $90^{\text {th }}$ percentile concentrations were $2.71 \mathrm{mg} / \mathrm{L}$ and $0.90 \mathrm{mg} / \mathrm{L}$, respectively. ${ }^{25}$ These comparisons illustrate how the PM concentration values between the subgroups of the two large databases may or may not match, giving additional grounds for interpretation.

Drug metabolites may have similar (e.g. $N$-desmethylamitriptyline) or different (e.g. $N$ desmethylclomipramine) pharmacodynamic properties than their respective parent compounds, or they may be pharmacologically inactive (e.g. $N$-desmethylcitalopram) ${ }^{27}$ For those drugs with similar properties, the sum of the concentrations of parent drug and active metabolite can be used for interpretation. Even non-active metabolites are important from a pharmacokinetic perspective, because the metabolite-to-parent drug ratio (MPR) can be used for differentiating between acute and chronic intake. ${ }^{23}$ MPR sometimes allows identification of abnormal metabolism caused by pharmacokinetic interactions or genetic abnormalities, ${ }^{28}$ especially when compared with established ratios from therapeutic drug monitoring. ${ }^{27}$ As has been pointed out earlier, the PM concentrations of drugs of abuse, such as parenterally administered strong opioids ${ }^{12,29,30}$ and stimulants, ${ }^{31}$ are of limited value in assessing the cause of death because individual tolerance, route of administration, and polydrug abuse are more important factors in these cases. However, MPR can be decisive in interpreting the role of drugs in abuser deaths. ${ }^{32}$ In this study, we were able to report the PM concentrations of a limited number of drug metabolites, but we acknowledge that a wider range of metabolites is needed. 
Interest is currently focused on the quantification of drugs in PM materials other than blood, including bile, brain, liver, muscle, and vitreous humor. ${ }^{33-38}$ However, while these alternative materials show promising results with individual drugs or in specific circumstances, femoral venous blood still represents the most viable material for interpretative purposes in PM toxicology, with a more extensive range of reference concentrations published in the literature.

\section{Conclusions}

We have provided an extended list of drug concentration distributions in PM femoral venous blood, accumulated during an 18-year period by using quality-controlled and mostly accredited methods. The data are intact in the sense that no preselection of cases has occurred according to the cause of death or any criterion other than the number of qualified findings per drug. Hence, there is no prior interpretation by a pathologist or toxicologist that might create a bias. The reader should use the data in case work with consideration and taking into account all of the necessary circumstantial and contributory factors related to the case. The strength of the present all-causes-of-death approach is that it provides abundant data for a statistically reliable basis for 'normal' PM drug concentrations in blood and even offers potential for answering the question 'was it a poisoning?' - but only in the right context. 


\section{References}

1. Madea B (Editor). Handbook of Forensic Medicine, Wiley-Blackwell, Chichester 2014.

2. Lahti RA, Vuori E. Fatal drug poisonings: medico-legal reports and mortality statistics. Forensic Sci Int. 2003;136(1-3):35-46.

3. Ojanperä I, Kriikku P, Vuori E. Fatal toxicity index of medicinal drugs based on a comprehensive toxicology database. Int J Legal Med. 2016;130(5):1209-1216.

4. Kriikku P, Häkkinen M, Ojanperä I. High buprenorphine-related mortality is persistent in Finland. Forensic Sci Int. 2018;291:76-82.

5. Baselt RC. Disposition of Toxic Drugs and Chemicals in Man, $11^{\text {th }}$ Ed., Biomedical Publications, Seal Beach 2017.

6. Prouty RW, Anderson WH. A comparison of postmortem heart blood and femoral blood ethyl alcohol concentrations. J Anal Toxicol. 1987;11(5):191-7.

7. Prouty RW, Anderson WH. The forensic science implications of site and temporal influences on postmortem blood-drug concentrations. J Forensic Sci. 1990;35(2):243-70.

8. Pounder DJ, Jones GR. Post-mortem drug redistribution - a toxicological nightmare. Forensic Sci Int. 1990;45(3):253-263

9. Holt DW, Benstead JG. Postmortem assay of digoxin by radioimmunoassay. J Clin Pathol. 1975;28(6):483-486.

10. Ferner RE. Post-mortem clinical pharmacology. Br J Clin Pharmacol. 2008;66(4):430-443.

11. Zilg B, Thelander G, Giebe B, Druid H. Postmortem blood sampling-Comparison of drug concentrations at different sample sites. Forensic Sci Int. 2017;278:296-303.

12. Druid H. Postmortem toxicology: The Toxicolist story. TIAFT Bulletin 2018;48(2):16-20.

13. Jones AW, Holmgren A. Concentration distributions of the drugs most frequently identified in post-mortem femoral blood representing all causes of death. Med Sci Law. 2009;49(4):257-273.

14. Launiainen T, Ojanperä I. Drug concentrations in post-mortem femoral blood compared with therapeutic concentrations in plasma. Drug Test Anal. 2014;6(4):308-316.

15. Ojanperä I, Rasanen I, Vuori E. Automated quantitative screening for acidic and neutral drugs in whole blood by dual-column capillary gas chromatography. J Anal Toxicol. 1991;15(4):204-208.

16. Launiainen T, Sajantila A, Rasanen I, Vuori E, Ojanperä I. Adverse interaction of warfarin and paracetamol: evidence from a post-mortem study. Eur J Clin Pharmacol. 2010;66(1):97-103.

17. Rasanen I, Ojanperä I, Vuori E. Quantitative screening for benzodiazepines in blood by dualcolumn gas chromatography and comparison of the results with urine immunoassay. J Anal Toxicol. 2000;24(1):46-53. 
18. Gunnar T, Ariniemi K, Lillsunde P. Fast gas chromatography-negative-ion chemical ionization mass spectrometry with microscale volume sample preparation for the determination of benzodiazepines and alpha-hydroxy metabolites, zaleplon and zopiclone in whole blood. J Mass Spectrom. 2006;41(6):741-754.

19. Rasanen I, Kontinen I, Nokua J, Ojanperä I, Vuori E. Precise gas chromatography with retention time locking in comprehensive toxicological screening for drugs in blood. J Chromatogr B Analyt Technol Biomed Life Sci. 2003;788(2):243-250.

20. Viinamäki J, Ojanperä I. Photodiode array to charged aerosol detector response ratio enables comprehensive quantitative monitoring of basic drugs in blood by ultra-high performance liquid chromatography. Anal Chim Acta. 2015;865:1-7.

21. Schulz M, Iwersen-Bergmann S, Andresen H, Schmoldt A. Therapeutic and toxic blood concentrations of nearly 1,000 drugs and other xenobiotics. Crit Care. 2012;16(4):R136.

22. Druid H, Holmgren P. A compilation of fatal and control concentrations of drugs in postmortem femoral blood. J Forensic Sci. 1997;42(1):79-87.

23. Reis M, Aamo T, Ahlner J, Druid H. Reference concentrations of antidepressants. A compilation of postmortem and therapeutic levels. J Anal Toxicol. 2007;31(5):254-264.

24. Jönsson AK, Söderberg C, Espnes KA, Ahlner J, Eriksson A, Reis M, Druid H. Sedative and hypnotic drugs--fatal and non-fatal reference blood concentrations. Forensic Sci Int. 2014;236:138145.

25. Söderberg C, Wernvik E, Tillmar A, Spigset O, Kronstrand R, Reis M, Jönsson AK, Druid H. Antipsychotics - Postmortem fatal and non-fatal reference concentrations. Forensic Sci Int. 2016;266:91-101.

26. Söderberg C, Wernvik E, Jönsson AK, Druid H. Reference values of lithium in postmortem femoral blood. Forensic Sci Int. 2017;277:207-214.

27. Hiemke C, Bergemann N, Clement HW, Conca A, Deckert J, Domschke K, Eckermann G, Egberts K, Gerlach M, Greiner C, Gründer G, Haen E, Havemann-Reinecke U, Hefner G, Helmer R, Janssen G, Jaquenoud E, Laux G, Messer T, Mössner R, Müller MJ, Paulzen M, Pfuhlmann B, Riederer P, Saria A, Schoppek B, Schoretsanitis G, Schwarz M, Gracia MS, Stegmann B, Steimer W, Stingl JC, Uhr M, Ulrich S, Unterecker S, Waschgler R, Zernig G, Zurek G, Baumann P. Consensus Guidelines for Therapeutic Drug Monitoring in Neuropsychopharmacology: Update 2017. Pharmacopsychiatry. 2018;51(1-2):9-62.

28. Lam J, Woodall KL, Solbeck P, Ross CJ, Carleton BC, Hayden MR, Koren G, Madadi P. Codeine-related deaths: The role of pharmacogenetics and drug interactions. Forensic Sci Int. 2014;239:50-56.

29. Jones AW, Holmgren A. Concentration ratios of free-morphine to free-codeine in femoral blood in heroin-related poisoning deaths. Leg Med (Tokyo). 2011;13(4):171-173.

30. Häkkinen M, Launiainen T, Vuori E, Ojanperä I. Benzodiazepines and alcohol are associated with cases of fatal buprenorphine poisoning. Eur J Clin Pharmacol. 2012;68(3):301-309. 
31. Verschraagen M, Maes A, Ruiter B, Bosman IJ, Smink BE, Lusthof KJ. Post-mortem cases involving amphetamine-based drugs in The Netherlands. Comparison with driving under the influence cases. Forensic Sci Int. 2007;170(2-3):163-170.

32. Häkkinen M, Launiainen T, Vuori E, Ojanperä I. Comparison of fatal poisonings by prescription opioids. Forensic Sci Int. 2012;10;222(1-3):327-331.

33. Ferner RE, Aronson JK. The toxicological significance of post-mortem drug concentrations in bile. Clin Toxicol (Phila). 2018;56(1):7-14.

34. Kronstrand R, Forsman M, Roman M. Quantitative analysis of drugs in hair by UHPLC high resolution mass spectrometry. Forensic Sci Int. 2018;283:9-15.

35. Maskell PD, Wilson NE, Seetohul LN, Crichton ML, Beer LJ, Drummond G, De Paoli G. Postmortem tissue distribution of morphine and its metabolites in a series of heroin-related deaths. Drug Test Anal. 2019;11(2):292-304.

36. Nielsen MKK, Nedahl M, Johansen SS, Linnet K. Validation of a fully automated solid-phase extraction and ultra-high-performance liquid chromatography-tandem mass spectrometry method for quantification of 30 pharmaceuticals and metabolites in post-mortem blood and brain samples. Drug Test Anal. 2018;10(7):1147-1157.

37. Palmiere C, Sabatasso S, Torrent C, Rey F, Werner D, Bardy D. Post-mortem determination of insulin using chemiluminescence enzyme immunoassay: preliminary results. Drug Test Anal. 2015;7(9):797-803.

38. Rees KA, Seulin S, Yonamine M, Leyton V, Munoz DR, Gianvecchio VA, Pounder DJ, Osselton MD. Analysis of skeletal muscle has potential value in the assessment of cocaine-related deaths. Forensic Sci Int. 2013;226(1-3):46-53.

39. Nagasaki T, Ohkubo T, Sugawara K, Yasui N, Otani K, Kaneko S. Determination of alprazolam and $\alpha$-hydroxyalprazolam in plasma by high-performance liquid chromatography. Anal Sci $1997 ; 13 ; 245-249$.

40. Stead AH, Moffat AC. A collection of therapeutic, toxic and fatal blood drug concentrations in man. Human Toxicol. 1983;3; 437.

41. Huestis MA, Cone EJ, Pirnay SO, Umbricht A, Preston KL. Intravenous buprenorphine and norbuprenorphine pharmacokinetics in humans. Drug Alcohol Depend. 2013;131(3); 258-262.

42. Lamberg TS, Kivistö KT, Neuvonen PJ. Concentrations and effects of buspirone are considerably reduced by rifampicin. Br J Clin Pharmacol. 1998;45;381-385.

43. Ozbey G, Yucel B, Eren Bodur N, Erdogan Taycan S, Arslan T, Cerit N, Yuksel N, Cuneyt Guzey I, Uluoglu C. Serum N-desmethylcitalopram concentrations are associated with the clinical response to citalopram of patients with major depression. Psychiatry Investig. 2018;15(3);313-319.

44. Osselton MD. Toxicological tables: a compendium of pharmacological, therapeutic and toxicological data on 136 drugs and chemicals in humans. Bull Int Assoc Forens Toxicol. $1973 ; 17(1) ; 16-33$. 
45. Jawad S, Richens A, Oxley J. Single dose pharmacokinetic study of clobazam in normal volunteers and epileptic patients. Br J Clin Pharmac. 1984;18; 873-877.

46. Mavissakalian M, Jones B, Olson S, Perel JM. The relationship of plasma clomipramine and ndesmethylclomipramine to response in obsessive-compulsive disorder. Psychopharmacol Bull 1990;26;119-122.

47. Naestoft J, Larsen NE. Quantitative determination of clonazepam and its metabolites in human plasma by gas chromatography. J Chromatogr. 1974;93;113-122.

48. Uges DRA. Therapeutic and toxic drug concentrations. Bull Int Assoc Forens Toxicol. 1996;26; (1 supplement) 1 .

49. Kazierad DJ, Martin DE, Bhun RA, Tenero DM, Ilson B, Boike SC, Etheredge R, Jorkasky DIL. Effect of fluconazole on the pharmacokinetics of eprosartan and losartan in healthy male volunteers. Clin Pharmacol Ther. 1997;62:417-25.

50. Tybring G, Otani K, Kaneko S, Mihara K, Fukushima Y, Bertilsson L. Enantioselective determination of mianserin and its desmethyl metabolite in plasma during treatment of depressed Japanese patients. Ther Drug Monit. 1995;17(5):516-21.

51. Heizmann P, Eckert M, Ziegler WH. Pharmacokinetics and bioavailabilty of midazolam in man. Br J Clin Pharmac. 1983; 16; 43S-49S.

52. Budde K, Neumayer H-H, Fritsche L, Sulowicz W, Stompôr T, Eckland D. The pharmacokinetics of pioglitazone in patients with impaired renal function. Br J Clin Pharmacol. $2003 ; 55 ; 368-374$.

53. Stangier J, Su C, Roth W. Pharmacokinetics of orally and intravenously administered telmisartan in healthy young and elderly volunteers and in hypertensive patients. J Int Med Res. 2000;28:149 - 167 .

54. Tanaka H, Naito T, Mino Y, Kawakami J. Validated determination method of tramadol and its desmethylates in human plasma using an isocratic LC-MS/MS and its clinical application to patients with cancer pain or non-cancer pain. J Pharm Health Care Sci. 2016;2;25-33.

55. de Moraes NV, Lauretti GR, Napolitano MN, Santos NR, Godoy ALPC, Lanchote VL. Enantioselective analysis of unbound tramadol, O-desmethyltramadol and N-desmethyltramadol in plasma by ultrafiltration and LC-MS/MS: Application to clinical pharmacokinetics. J Chromatogr B 2012; 880;140-147.

56. Suckow RF, Cooper TB. Determination of trimipramine and metabolites in plasma by liquid chromatography with electrochemical detection. J Pharm Sci. 1984;73;1745-1748.

57. Hermann M, Hendset M, Fosaas K, Hjerpset M, Refsum H. Serum concentrations of venlafaxine and its metabolites $\mathrm{O}$-desmethylvenlafaxine and $\mathrm{N}$-desmethylvenlafaxine in heterozygous carriers of the CYP2D6*3, *4 or *5 allele. Eur J Clin Pharmacol. 2008;64;483-487.

58. Henness S, Keam SJ. Vildagliptin. Drugs. 2006;66;1989-2001. 
59. Areberg J, Petersen KB, Chen G, Naik H. Population pharmacokinetic meta-analysis of vortioxetine in healthy individuals. Basic Clin Pharmacol Toxicol. 2014;115;552-559. 
Table 1. Demographics and mean blood alcohol concentration for autopsy cases with comprehensive post-mortem drug analysis completed.

\begin{tabular}{|l|c|c|c|c|}
\hline Sex & $\mathrm{N}$ & Age, years & $\mathrm{N}^{\mathrm{a}}$ & $\begin{array}{c}\text { Blood ethanol, \%o (g/kg) } \\
\text { Mean (median) highest }\end{array}$ \\
\hline Male & & Mean (median) highest & $35,889(81 \%)$ & $1.71(1.60) 7.7$ \\
\hline Female & $90,398(74 \%)$ & $56.5(58) 103$ & $8,243(19 \%)$ & $1.64(1.50) 8.5$ \\
\hline Both sexes & $122,234(100 \%)$ & $61.9(64) 105$ & $44,132(100 \%)$ & $1.70(1.60) 8.5$ \\
\hline
\end{tabular}

${ }^{\mathrm{a} B l o o d}$ ethanol $\geq 0.2 \%$ 
Table 2. Descriptive statistics for concentrations of drugs determined in post-mortem (PM) femoral blood representing all causes of death.

\begin{tabular}{|c|c|c|c|c|c|c|c|c|c|c|}
\hline \multirow[t]{2}{*}{ Drug } & \multirow{2}{*}{$\begin{array}{c}\mathrm{PM} \\
\text { cases } \\
\mathrm{N}\end{array}$} & \multirow{2}{*}{$\begin{array}{c}\text { PM LOQ } \\
\text { mg/L }\end{array}$} & \multirow{2}{*}{$\begin{array}{c}\text { PM mean } \\
\text { mg/L }\end{array}$} & \multirow{2}{*}{$\begin{array}{c}\mathrm{PM} \\
\text { median } \\
\mathrm{mg} / \mathrm{L}\end{array}$} & \multicolumn{3}{|c|}{ Upper PM percentiles mg/L } & \multirow{2}{*}{ 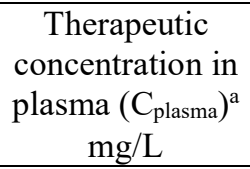 } & \multirow{2}{*}{$\begin{array}{l}\text { Previous } \\
\text { PM } \\
\text { median }^{\mathrm{b}} \\
\mathrm{mg} / \mathrm{L} \\
\end{array}$} & \multirow{2}{*}{$\begin{array}{c}\text { Difference in PM } \\
\text { median from } \\
\text { previous data } \\
\% \\
\%\end{array}$} \\
\hline & & & & & $90^{\text {th }}$ & $95^{\text {th }}$ & $97.5^{\text {th }}$ & & & \\
\hline Acebutolol & 115 & 0.25 & 11 & 0.77 & 23 & 72 & 100 & 2 & 0.84 & -8 \\
\hline Alfentanil & 119 & 0.00005 & 0.029 & 0.016 & 0.08 & 0.10 & 0.16 & 0.60 & & \\
\hline Alprazolam & 2234 & 0.02 & 0.06 & 0.033 & 0.12 & 0.20 & 0.33 & 0.05 & 0.05 & -34 \\
\hline Alprazolam, 1-hydroxy- & 821 & 0.001 & 0.005 & 0.002 & 0.010 & 0.018 & 0.028 & $0.003^{39}$ & & \\
\hline Aminophenazone, 4-methyl- & 599 & $2 / 3^{d}$ & 21 & 12 & 50 & 67 & 96 & $10^{\mathrm{e}}$ & 15 & -20 \\
\hline Amiodarone & 137 & 0.4 & 3.9 & 1.8 & 8.0 & 11 & 18 & 2 & 1.8 & 0 \\
\hline Amitriptyline & 2604 & 0.1 & 1.3 & 0.40 & 2.6 & 4.6 & 7.9 & 0.30 & 0.40 & 0 \\
\hline Amitriptyline, $N$-desmethyl- & 1347 & 0.1 & 0.59 & 0.30 & 1.3 & 2.0 & 3.0 & $0.25^{40}$ & & \\
\hline Amlodipine & 3081 & 0.006 & 0.09 & 0.055 & 0.16 & 0.21 & 0.28 & 0.015 & 0.07 & -21 \\
\hline Amphetamine & 1087 & 0.04 & 0.80 & 0.26 & 1.9 & 2.9 & 4.4 & 0.10 & 0.28 & -7 \\
\hline Aripiprazole & 199 & 0.1 & 0.29 & 0.15 & 0.51 & 0.71 & 0.86 & 0.50 & & \\
\hline Atenolol & 668 & 0.2 & 1.5 & 0.69 & 2.6 & 4.3 & 6.1 & 1.0 & 0.64 & 9 \\
\hline Betaxolol & 156 & 0.003 & 0.20 & 0.10 & 0.31 & 0.40 & 0.43 & 0.05 & 0.10 & 0 \\
\hline Biperiden & 38 & 0.1 & 0.20 & 0.10 & 0.30 & 0.32 & 0.46 & 0.10 & 0.10 & 0 \\
\hline Bisoprolol & 7570 & 0.01 & 0.11 & 0.05 & 0.18 & 0.28 & 0.45 & 0.10 & 0.05 & 0 \\
\hline Bupivacaine & 99 & $0.2 / 0.05^{\mathrm{d}}$ & 1.5 & 0.36 & 1.3 & 3.3 & 4.7 & 1.5 & 0.40 & -10 \\
\hline Buprenorphine & 1549 & 0.0002 & 0.0033 & 0.0013 & 0.0059 & 0.0095 & 0.019 & 0.015 & 0.0012 & 8 \\
\hline Buprenorphine, nor- & 1251 & 0.0002 & 0.0038 & 0.0012 & 0.0078 & 0.014 & 0.025 & $0.005^{41}$ & & \\
\hline Bupropion & 204 & 0.1 & 3.7 & 0.28 & 7.2 & 17 & 42 & 0.10 & & \\
\hline Buspirone & 27 & 0.05 & 0.083 & 0.050 & 0.23 & 0.30 & 0.33 & $0.01^{42}$ & & \\
\hline Caffeine & 32721 & $1 / 3^{\mathrm{d}}$ & 4.7 & 3.9 & 8.5 & 11 & 14 & 10 & 3.0 & 30 \\
\hline Candesartan & 291 & 0.005 & 0.12 & 0.03 & 0.20 & 0.40 & 0.64 & 0.18 & & \\
\hline Carbamazepine & 2228 & $1 / 0.3^{\mathrm{d}}$ & 7.6 & 6.3 & 13 & 18 & 26 & 8.0 & 6.2 & 2 \\
\hline Carbamazepine, 10,11-dihydro-10-hydroxy- & 834 & $5 / 3^{d}$ & 27 & 22 & 50 & 62 & 80 & 35 & 22 & 0 \\
\hline Carvedilol & 253 & 0.003 & 0.040 & 0.018 & 0.080 & 0.13 & 0.30 & 0.15 & 0.02 & -10 \\
\hline Celiprolol & 177 & 0.03 & 3.3 & 0.27 & 2.7 & 5.3 & 8.7 & 0.50 & 0.28 & -4 \\
\hline Cetirizine & 112 & 0.001 & 0.67 & 0.11 & 0.90 & 1.9 & 3.0 & 0.30 & 0.10 & 10 \\
\hline Chlordiazepoxide & 2408 & 0.2 & 1.4 & 0.61 & 3.0 & 4.8 & 6.9 & 3.0 & 0.70 & -13 \\
\hline Chloroquine & 59 & 0.2 & 10 & 0.67 & 39 & 55 & 67 & 0.50 & 1.3 & -48 \\
\hline Chlorpromazine & 291 & 0.05 & 0.95 & 0.30 & 2.1 & 3.9 & 6.5 & 0.10 & 0.30 & 0 \\
\hline Chlorprothixene & 755 & 0.1 & 1.8 & 0.30 & 2.6 & 5.0 & 9.0 & 0.30 & 0.30 & 0 \\
\hline Citalopram & 5800 & 0.1 & 0.87 & 0.40 & 1.3 & 2.1 & 4.5 & 0.40 & 0.40 & 0 \\
\hline Citalopram, $N$-desmethyl- & 892 & $0.5 / 0.05^{\mathrm{d}}$ & 0.39 & 0.21 & 0.83 & 1.1 & 1.7 & $0.15^{43}$ & & \\
\hline Clobazam & 42 & $0.1 / 0.05^{\mathrm{d}}$ & 0.35 & 0.20 & 0.71 & 1.3 & 1.6 & $0.61^{44}$ & & \\
\hline Clobazam, $N$-desmethyl- & 101 & $0.2 / 0.05^{\mathrm{d}}$ & 1.6 & 0.90 & 3.4 & 5.5 & 8.6 & $1.5^{45}$ & & \\
\hline Clobutinol & 23 & $0.2 / 0.05^{\mathrm{d}}$ & 0.54 & 0.30 & 0.87 & 1.4 & 2.1 & 0.20 & & \\
\hline Clomipramine & 155 & 0.1 & 1.0 & 0.60 & 2.2 & 3.4 & 4.0 & 0.40 & & \\
\hline Clomipramine, $N$-desmethyl- & 81 & $0.5 / 0.05^{\mathrm{d}}$ & 2.7 & 1.2 & 4.8 & 7.1 & 20 & $1.0^{46}$ & & \\
\hline Clonazepam & 315 & 0.01 & 0.030 & 0.011 & 0.041 & 0.080 & 0.10 & 0.08 & 0.03 & -63 \\
\hline
\end{tabular}


Clonazepam, 7-amino-

Clozapine

Codeine

Cyclizine

Demoxepam

Desloratadine

Dextromethorphan

Dextropropoxyphene

Diazepam

Diazepam, $N$-desmethyl-

Diclofenac

Digoxin

Diltiazem

Diphenhydramine

Dixyrazine

Donepezil

Doxepin

Doxepin, $N$-desmethyl-

Duloxetine

Enalapril

Ephedrine

Ethylmorphine

Etoricoxib

Felodipine

Fentanyl

Flecainide

Fluconazole

Fluoxetine

Flupentixol

Fluvoxamine

Furosemide

Gabapentin

Galantamine

Glibenclamide

Glimepiride

Haloperidol

Hydrochlorothiazide

Hydroxychloroquine

Hydroxyzine

Ibuprofen

Indomethacin

Ketamine

Ketoprofen

Labetalol

Lacosamide

\begin{tabular}{|c|c|c|c|c|c|c|c|}
\hline 1790 & 0.005 & 0.17 & 0.094 & 0.38 & 0.56 & 0.83 & $0.14^{47}$ \\
\hline 880 & 0.1 & 2.7 & 1.1 & 4.3 & 8.7 & 16 & 0.60 \\
\hline 3633 & 0.02 & 0.65 & 0.14 & 1.4 & 2.7 & 4.6 & 0.25 \\
\hline 62 & 0.005 & 1.1 & 0.30 & 1.2 & 2.3 & 5.9 & 0.25 \\
\hline 727 & 0.1 & 1.1 & 0.80 & 2.5 & 3.1 & 4.0 & $2.8^{48}$ \\
\hline 56 & 0.001 & 0.071 & 0.031 & 0.13 & 0.24 & 0.44 & 0.006 \\
\hline 91 & 0.1 & 0.57 & 0.30 & 1.5 & 1.9 & 2.5 & 0.04 \\
\hline 270 & 0.1 & 6.6 & 2.6 & 12 & 18 & 41 & 0.30 \\
\hline 11831 & 0.02 & 0.17 & 0.090 & 0.40 & 0.60 & 0.80 & 2.0 \\
\hline 15945 & 0.02 & 0.21 & 0.10 & 0.50 & 0.70 & 0.99 & 0.80 \\
\hline 69 & $0.5 / 0.3^{\mathrm{d}}$ & 2.2 & 1.1 & 5.6 & 6.9 & 8.3 & 3.0 \\
\hline 2578 & 0.0005 & 0.0028 & 0.0018 & 0.0045 & 0.0063 & 0.0086 & 0.002 \\
\hline 422 & 0.1 & 2.4 & 0.30 & 1.8 & 7.8 & 22 & 0.13 \\
\hline 122 & 0.005 & 0.36 & 0.20 & 0.80 & 0.90 & 1.3 & 0.10 \\
\hline 57 & 0.003 & 0.79 & 0.10 & 1.9 & 5.7 & 6.9 & 0.30 \\
\hline 560 & 0.003 & 0.23 & 0.20 & 0.40 & 0.49 & 0.59 & 0.075 \\
\hline 902 & 0.05 & 2.2 & 0.60 & 6.3 & 10 & 15 & 0.20 \\
\hline 254 & $0.2 / 0.05^{\mathrm{d}}$ & 0.73 & 0.40 & 1.6 & 2.3 & 3.2 & 0.20 \\
\hline 320 & 0.01 & 0.40 & 0.15 & 0.63 & 1.2 & 2.7 & 0.12 \\
\hline 115 & 0.01 & 0.10 & 0.032 & 0.16 & 0.47 & 0.66 & 0.10 \\
\hline 357 & 0.04 & 0.50 & 0.20 & 0.90 & 1.5 & 2.3 & 0.20 \\
\hline 116 & 0.02 & 0.42 & 0.10 & 1.2 & 2.7 & 2.9 & 0.60 \\
\hline 141 & 0.5 & 2.9 & 1.5 & 5.0 & 6.3 & 8.6 & 3.6 \\
\hline 141 & 0.001 & 0.017 & 0.0020 & 0.040 & 0.060 & 0.15 & 0.012 \\
\hline 1074 & 0.0001 & 0.010 & 0.0042 & 0.019 & 0.030 & 0.047 & 0.01 \\
\hline 166 & 0.2 & 4.1 & 1.8 & 8.7 & 16 & 23 & 0.80 \\
\hline 443 & 0.1 & 7.8 & 4.3 & 20 & 29 & 37 & 5.0 \\
\hline 868 & 0.2 & 0.84 & 0.50 & 1.9 & 2.8 & 3.7 & 0.50 \\
\hline 43 & 0.001 & 0.020 & 0.0070 & 0.056 & 0.087 & 0.099 & 0.01 \\
\hline 96 & 0.03 & 2.4 & 0.70 & 7.3 & 8.4 & 19 & 0.23 \\
\hline 310 & 0.1 & 2.5 & 0.90 & 5.5 & 9.1 & 16 & 5.0 \\
\hline 541 & 1 & 27 & 12 & 58 & 93 & 145 & 6.0 \\
\hline 88 & 0.01 & 0.22 & 0.14 & 0.40 & 0.54 & 0.76 & 0.06 \\
\hline 45 & 0.08 & 0.28 & 0.09 & 0.31 & 0.63 & 0.69 & 0.20 \\
\hline 211 & 0.01 & 0.27 & 0.03 & 0.21 & 0.38 & 1.0 & 0.50 \\
\hline 335 & 0.003 & 0.02 & 0.009 & 0.03 & 0.046 & 0.12 & 0.017 \\
\hline 581 & 0.05 & 0.34 & 0.23 & 0.69 & 0.99 & 1.3 & 2.0 \\
\hline 394 & 1 & 12 & 8.0 & 26 & 33 & 45 & 0.10 \\
\hline 434 & 0.2 & 0.61 & 0.30 & 1.1 & 2.0 & 3.1 & 0.10 \\
\hline 1973 & 10 & 18 & 14 & 35 & 49 & 70 & 30 \\
\hline 51 & 0.5 & 1.3 & 1.0 & 2.1 & 3.0 & 3.9 & 1.0 \\
\hline 358 & 0.1 & 0.82 & 0.44 & 1.5 & 2.4 & 4.1 & 6.0 \\
\hline 249 & 0.3 & 3.3 & 1.2 & 5.7 & 10 & 21 & 3.7 \\
\hline 216 & 0.01 & 0.12 & 0.059 & 0.25 & 0.35 & 0.42 & 0.18 \\
\hline
\end{tabular}

\begin{tabular}{|c|c|}
\hline 1.1 & 0 \\
\hline 0.16 & -13 \\
\hline 0.30 & 0 \\
\hline 0.40 & -25 \\
\hline 2.6 & 0 \\
\hline 0.09 & 0 \\
\hline 0.10 & 0 \\
\hline 1.3 & -15 \\
\hline 0.30 & 0 \\
\hline 0.20 & 0 \\
\hline 0.10 & 0 \\
\hline 0.20 & 0 \\
\hline 0.60 & 0 \\
\hline 0.14 & 7 \\
\hline 0.21 & -5 \\
\hline 0.10 & 0 \\
\hline 1.2 & 25 \\
\hline 0.0058 & -28 \\
\hline 1.9 & -3 \\
\hline 3.8 & 13 \\
\hline 0.50 & 0 \\
\hline 0.70 & 0 \\
\hline 0.90 & 0 \\
\hline 11 & 9 \\
\hline 0.11 & 27 \\
\hline 0.03 & 0 \\
\hline 0.01 & -10 \\
\hline 10 & -20 \\
\hline 0.30 & 0 \\
\hline 19 & -26 \\
\hline 1.1 & -9 \\
\hline 0.50 & -12 \\
\hline 1.3 & -8 \\
\hline 0.09 & -34 \\
\hline
\end{tabular}


Lamotrigine

Levetiracetam

evomepromazine

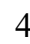

Lidocaine

Lithium

Lorazepam

Losartan

Losartan, carboxylic acid (EXP3174)

MDA

\section{MDMA}

Meloxicam

Melperone

Memantine

Meprobamate

Mesoridazine

Metformin

Methadone

Methamphetamine

Methylphenidate

Metoclopramide

Metoprolol

Mianserin

Mianserin, $N$-desmethyl-

Midazolam

Midazolam, 1-hydroxy-

Mirtazapine

Moclobemide

Morphine

Naloxone

Naproxen

Nifedipine

Nitrazepam

Olanzapine

Orphenadrine

Oxazepam

Oxcarbazepine

Oxycodone

Paliperidone (9-hydroxyrisperidone)

Paracetamol

Paroxetin

Pentobarbital

Perphenazine

Pethidine

Phenazepam

Phenobarbital

$\begin{array}{ccccccc}691 & 1 / 0.5^{\mathrm{d}} & 4.9 & 3.0 & 10 & 15 & 24 \\ 457 & 3 & 28 & 18 & 61 & 78 & 90 \\ 2274 & 0.1 & 1.1 & 0.31 & 1.9 & 3.2 & 5.1 \\ 3853 & 0.1 & 0.75 & 0.34 & 1.7 & 2.5 & 3.9 \\ 223 & 0.5 & 3.9 & 2.5 & 7.5 & 11 & 19 \\ 1676 & 0.01 & 0.04 & 0.02 & 0.07 & 0.10 & 0.20 \\ 720 & 0.005 & 0.13 & 0.03 & 0.27 & 0.48 & 0.80 \\ 602 & 0.005 & 0.12 & 0.05 & 0.26 & 0.52 & 0.79 \\ 47 & 0.05 & 0.13 & 0.07 & 0.19 & 0.45 & 1.0 \\ 139 & 0.04 & 1.1 & 0.49 & 3.0 & 3.7 & 5.0 \\ 40 & 0.2 & 2.2 & 1.4 & 5.5 & 9.0 & 9.1 \\ 174 & 0.05 & 1.6 & 0.40 & 3.4 & 9.4 & 16 \\ 302 & 0.02 & 0.74 & 0.48 & 1.6 & 2.0 & 2.4 \\ 194 & 10 & 18 & 3.3 & 52 & 72 & 83 \\ 88 & 0.2 & 0.74 & 0.50 & 1.2 & 1.6 & 2.6 \\ 3386 & 1 & 14 & 5.1 & 34 & 61 & 92 \\ 466 & 0.05 & 0.63 & 0.50 & 1.4 & 1.7 & 2.0 \\ 185 & 0.04 & 0.86 & 0.18 & 1.2 & 2.1 & 2.8 \\ 30 & 0.05 / 0.1^{\mathrm{d}} & 0.20 & 0.10 & 0.28 & 0.38 & 0.83 \\ 1209 & 0.05 & 0.21 & 0.10 & 0.40 & 0.60 & 0.80 \\ 3681 & 0.05 & 0.90 & 0.20 & 1.1 & 1.9 & 4.0 \\ 487 & 0.05 & 0.37 & 0.20 & 0.70 & 1.1 & 2.0 \\ 130 & 0.1 & 0.47 & 0.30 & 0.80 & 1.1 & 1.5 \\ 445 & 0.02 & 0.12 & 0.046 & 0.24 & 0.46 & 0.60 \\ 621 & 0.002 & 0.053 & 0.008 & 0.10 & 0.18 & 0.30 \\ 3820 & 0.05 & 0.45 & 0.19 & 0.70 & 1.5 & 2.7 \\ 177 & 0.1 & 14 & 1.9 & 36 & 49 & 120 \\ 2134 & 0.02 & 0.21 & 0.070 & 0.35 & 0.61 & 0.95 \\ 167 & 0.0006 & 0.0082 & 0.0020 & 0.013 & 0.023 & 0.033 \\ 847 & 10 & 33 & 23 & 66 & 89 & 110 \\ 74 & 0.02 & 0.20 & 0.067 & 0.29 & 0.53 & 0.73 \\ 86 & 0.05 & 0.080 & 0.034 & 0.20 & 0.30 & 0.49 \\ 2215 & 0.05 & 0.45 & 0.20 & 0.80 & 1.4 & 2.4 \\ 551 & 0.1 & 0.94 & 0.34 & 1.8 & 3.3 & 5.9 \\ 9467 & 0.02 & 0.28 & 0.072 & 0.69 & 1.2 & 1.9 \\ 269 & 0.3 & 1.6 & 0.70 & 3.4 & 5.6 & 8.6 \\ 3114 & 0.02 & 0.29 & 0.08 & 0.45 & 0.80 & 1.5 \\ 193 & 0.002 & 0.021 & 0.013 & 0.040 & 0.060 & 0.10 \\ 9579 & 5 / 10^{\mathrm{d}} & 36 & 18 & 67 & 120 & 200 \\ 482 & 0.004 & 0.69 & 0.24 & 1.2 & 2.0 & 3.4 \\ 38 & 0.5 & 7.3 & 2.5 & 26 & 27 & 30 \\ 477 & 0.005 & 0.070 & 0.010 & 0.070 & 0.17 & 0.36 \\ 59 & 0.1 & 0.52 & 0.30 & 1.1 & 1.3 & 1.8 \\ 116 & 0.03 & 0.090 & 0.050 & 0.21 & 0.29 & 0.38 \\ 46 & 10 & 20 & 16 & 45 & 53 & 55\end{array}$

14

3.8

$0.60^{49}$

0.35

2.00

0.10

0.15

10

1.0

1.0
0.50

0.10

0.06

0.15

0.50

$0.13^{40}$

$0.08^{50}$

0.10

$0.40^{51}$

0.08

1.0

0.10

0.03

50

0.15

0.10

0.08

0.20

1.5

2.0

0.10

$0.06^{27}$

$\begin{array}{ccc}25 & 15 & 20 \\ 0.05 & 0.24 & 0\end{array}$

5.0

0.02

0.80

0.04

0.01

0.30

0.09

30 
Phenylpropanolamine

Phenytoin

codine

Pioglitazone

Pregabalin

Prilocaine

Promazine

Propofol

Propranolol

Pseudoephedrine

Quetiapine

Quinine

Risperidone

Rivastigmine

Ropivacaine

Rosiglitazone

Salicylic acid

Sertraline

Sildenafil

Sitagliptin

Sotalol

Sulpiride

Sumatriptan

Telmisartan

Temazepam

Tetrahydrocannabinol

THC, 11-hydroxy-

THC-COOH (11-nor-9-carboxy-THC)

Theobromine

Theophylline

Thiopental

Thioridazine

Tizanidine

Topiramate

Tramadol

Tramadol, $N$-desmethyl-

Tramadol, $O$-desmethyl-

Trazodone

Trimethoprim

Trimipramine

Trimipramine, $\mathrm{N}$-desmethyl-

Valproic acid

Valsartan

Venlafaxine

Warfarin
0.04

10

0.31

0.02

8.6
0.37

$0.01 \quad 0.15$

$\begin{array}{cc}0.2 & 18 \\ 0.1 / 0.05^{\mathrm{d}} & 0.79\end{array}$

0.1

0.1
$0.1 / 0.5^{\mathrm{d}}$

0.02

0.04

0.2

0.2
0.002

0.003

0.1

0.05
$5 / 3^{\mathrm{d}}$

0.1

0.03

0.01

0.25

0.02

0.01

0.005

0.02
0.001
0.003

0.003

0.003

2

10

0.1

0.003

$1 / 3^{\mathrm{d}}$

0.1

$0.2 / 0.1^{\mathrm{d}}$

0.2

1

0.1
$0.1 / 0.05$

$1 / 3^{\mathrm{d}}$

$1 / 3^{d}$
0.005

0.005
0.1
0.5

0.5

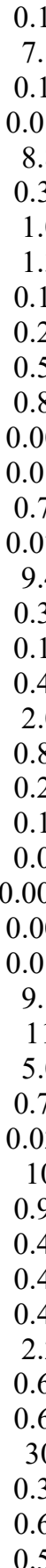

0.55
16
0.82
0.36
39
1.6
11
5.6
4.7
1.5
6.4
3.8
0.02
0.05
2.8
0.23
60
1.0
0.40
1.4
5.8
8.3
2.4
1.0
0.88
0.0092
0.020
0.070
19
24
15
3.0
0.2
24
7.1
2.3
1.7
4.3
6.5
2.4
2.3
75
4.2
5.4
1.0
0.50

15

0.20

8.3

2.0

0.05

8.0

0.30

0.80
0.50

7.0

0.006

0.02

1.5

0.30

200

0.25

0.50

0.38

3.0

0.40

0.06

$4.0^{53}$

0.15

0.01

0.016

0.030

0.029

0.050

0.14
29

$29 \quad 15$

15

5.0

2.0

0.01

10
1.0

1.0
$0.30^{54,55}$

$0.30^{54,55}$
$0.30^{54,55}$

$\begin{array}{ccc}1.0 & 0.40 & 20 \\ 2.5 & 2.3 & -4 \\ 0.30 & 0.60 & 0 \\ 0.40^{56} & & \\ 100 & 28 & 7 \\ 6.0 & & \\ 0.40 & 0.70 & 0 \\ 3.0 & 0.60 & -19\end{array}$

$-14$

$\begin{array}{cc}0.14 & -14 \\ 13 & -40 \\ 0.19 & -11\end{array}$

0.19

8.0

1.2

1.3

0.13

0.24
0.90

1.0

0.004

0.01

0.70

11

0.30

0.10

0.36

2.0

1.1

0.09

0.002

0

20

15

$-27$

0.70

0.02

8.8

0.90

0

30

14

$\begin{array}{ll}14 & 22 \\ 4.1 & 6.0\end{array}$

$\begin{array}{ll}4.1 & 6.0 \\ 2.4 & 3.8\end{array}$

$\begin{array}{ll}7.5 & 15\end{array}$

$\begin{array}{ll}9.0 & 12\end{array}$

$\begin{array}{ll}3.4 & 5.0\end{array}$

$3.2 \quad 3.6$

$99 \quad 193$

$\begin{array}{ll}5.8 & 13\end{array}$

0.60

$-19$ 


\begin{tabular}{|c|c|c|c|c|c|c|c|c|c|c|}
\hline Venlafaxine, $N$-desmethyl- & 36 & 0.05 & 0.47 & 0.40 & 0.96 & 1.3 & 1.4 & $0.50^{57}$ & & \\
\hline Venlafaxine, $O$-desmethyl- & 362 & 0.1 & 0.85 & 0.47 & 1.6 & 2.6 & 3.8 & $0.50^{57}$ & & \\
\hline Verapamil & 249 & 0.1 & 2.2 & 0.40 & 5.8 & 11 & 13 & 0.25 & 0.35 & 14 \\
\hline Vildagliptin & 38 & 0.05 & 0.11 & 0.059 & 0.27 & 0.38 & 0.40 & $1.6^{58}$ & & \\
\hline Vortioxetine & 43 & 0.003 & 0.14 & 0.090 & 0.17 & 0.29 & 0.47 & $0.07^{59}$ & & \\
\hline Xylometazoline & 23 & 0.05 & 0.008 & 0.001 & 0.004 & 0.011 & 0.070 & & & \\
\hline Zolpidem & 557 & 0.1 & 0.64 & 0.29 & 1.3 & 1.9 & 3.4 & 0.15 & 0.30 & -3 \\
\hline Zopiclone & 5778 & 0.02 & 0.33 & 0.08 & 0.66 & 1.3 & 2.5 & 0.05 & 0.10 & -20 \\
\hline Zuclopenthixol & 274 & 0.005 & 0.10 & 0.05 & 0.20 & 0.35 & 0.51 & 0.05 & 0.05 & 0 \\
\hline
\end{tabular}

${ }^{a}$ Upper limit of established therapeutic concentration in plasma $\left(\mathrm{C}_{\text {plasma }}\right)$ derived from Schulz et al. (ref. 21$)$ unless another reference indicated as superscript ${ }^{\mathrm{b}} \mathrm{PM}$ median concentration from previously published data by Launiainen and Ojanperä (ref. 14)

${ }^{\mathrm{c}}$ Difference in PM median concentration between current data and previously published data by Launiainen and Ojanperä (ref. 14)

${ }^{\mathrm{d}}$ Data combined from two successive methods; validation parameters presented in order of appearance

${ }^{\mathrm{e}}$ For parent drug metamizole 